\title{
Shape Memory and Superelasticity Authors Presented at IMAT-The Virtual Edition
}

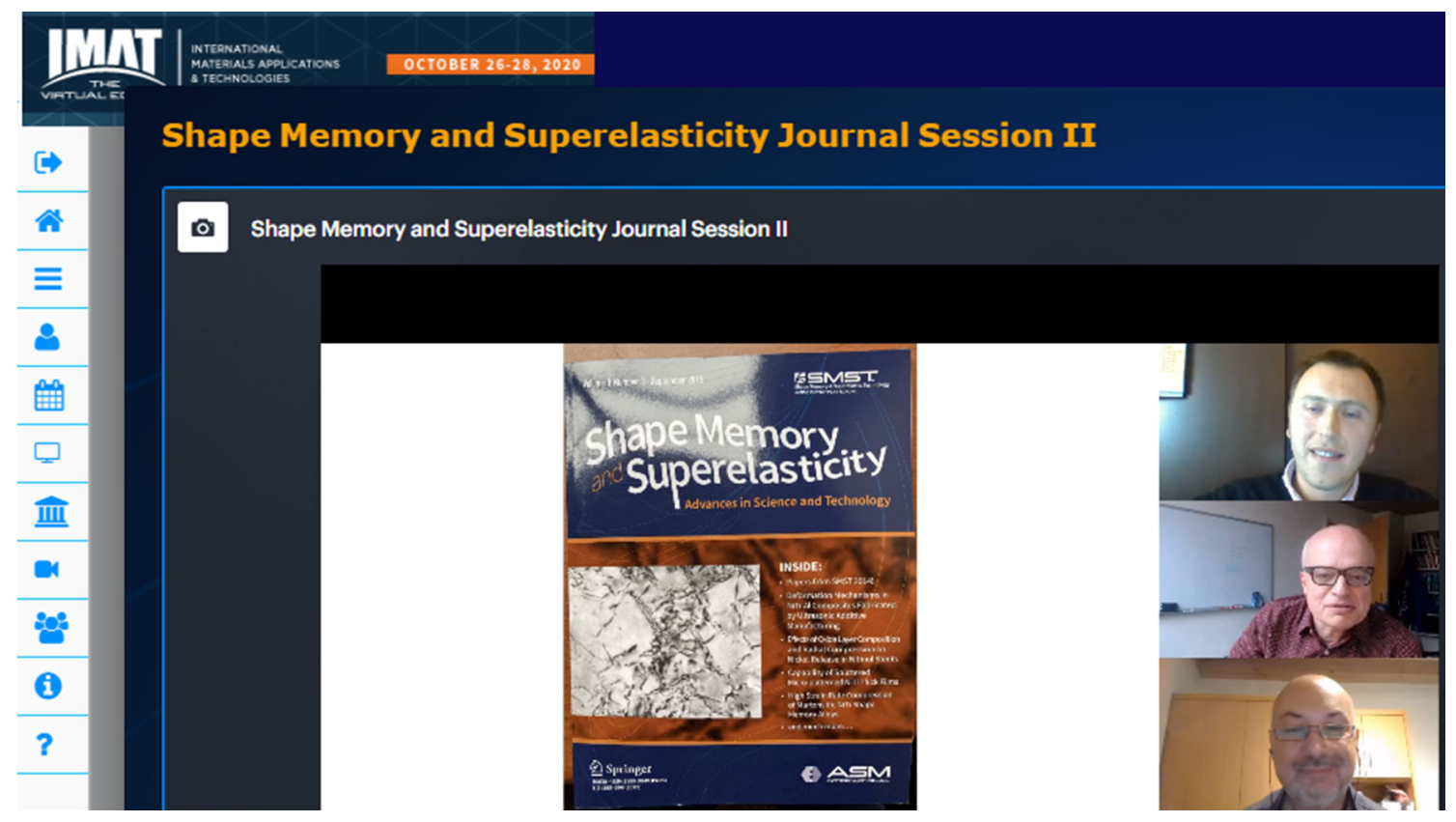

The inaugural International Materials Applications and Technologies (IMAT) 2020 Conference, ASM International's Annual Meeting, originally scheduled for September 14-17, 2020, in Cleveland, Ohio, made the difficult decision to cancel due to the COVID-19 pandemic. In its place, ASM was proud to present IMAT-The Virtual Edition on October 26-28, 2020.

Shape Memory and Superelasticity was pleased to be a part of virtual IMAT by hosting a session on Tuesday, October 27, 2020. The session was hosted by journal editor-in-chief, Huseyin Sehitoglu, University of Illinois at Urbana-Champaign, and included six prerecorded presentations, each followed by a live question and answer session with the presenter.

The presentations were:

High-Temperature Shape Memory Alloys-Recent Developments and Future Perspectives

Hans J. Maier, Institut für Werkstoffkunde (Materials Science), Leibniz Universität Hannover, Germany

Martensite as a Key to Unlock the Ideal Strength in Solids 
Yinong Liu, Department of Mechanical Engineering, The University of Western Australia, Perth, Australia

The (20-1)-Interfaces in Plastically Formed NiTi Martensite-Twins or 'Kwinks'?

Hanus Seiner, Institute of Thermomechanics, Czech Academy of Sciences, Prague, Czech Republic

\section{Strain-Sensitive Topological Evolution of Twin} Boundaries

Huseyin Sehitoglu, Department of Mechanical Science and Engineering, University of Illinois at Urbana- Champaign, USA

Lattice Defects Generated by Cyclic Thermomechanical Loading of Nanocrystalline NiTi Wires

Petr Sittner, Institute of Physics, Czech Academy of Sciences, Prague, Czech Republic

\section{Martensitic Phase Transformations of NiTi} Nanocrystals

Thomas Waitz, University of Vienna, Faculty of Physics, Physics of Nanostructured Materials, Vienna, Austria

These presentations are available to view at https:// www.asminternational.org. Expanded papers based on these sessions are planned for a future issue of the journal. Thank you to all who participated in this session of IMAT - The Virtual Edition. 